\title{
COMPARATIVE EVALUATION OF EFFECTIVENESS OF ALLOPLASTIC SKIN SUBSTITUTE "SUPRATHEL" AND HISTOEQUIVALENT-BIOPLASTIC MATERIAL FOR TREATMENT OF BURN WOUNDS
}

\section{A.A.Alekseev, N.B.Malutina, Y.I.Turnikov, A.E.Mitichkin, S.V.Popov. \\ Russian Medical Academy of continuous Postgraduate Education, Moscow, Russia.}

Objectives: To investigate effectiveness of alloplastic skin substitute "Suprathel" for treating burn wounds.

Methods: "Suprathel" is a microporous membrane, consisting of copolymer of polylactide and other polymers. In conditions of wound healing, this synthetic material performs substitute function of damaged skin and stimulates regeneration.

Before using materials, II-III degree burn wounds underwent dermabrasion by synthetic brush, electric dermatome, or hydrosurgical system "Versajet". Patients from group of comparison were treated using histoequivalent-bioplastic material G-DERM (membrane based on hyaluronic acid and collagen).

The results are shown in the tables below.

Discussion/Conclusion: Application of alloplastic skin substitute "Suprathel" provides effective treatment for border and mosaic II-III degree burn wounds.

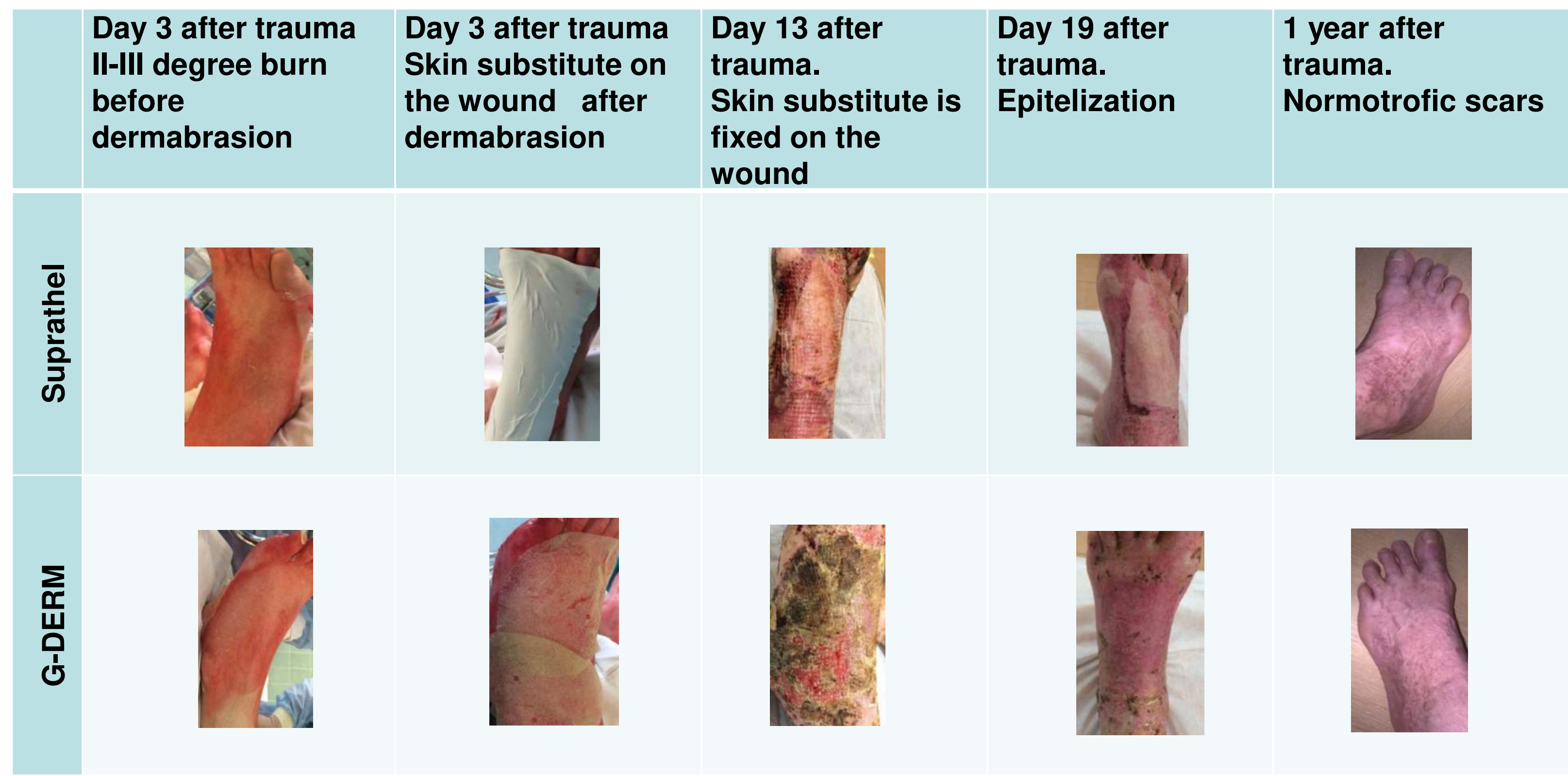

\begin{tabular}{|c|}
\hline Parameters \\
Number of patients \\
Time of epithelization (days \\
after injury) \\
Wounds required auto skin \\
grafting (\%) \\
Pain during dressing change \\
(score)
\end{tabular}

Alloplastic skin substitute "Suprathel"

20

$14,8 \pm 1,6$

10

$2,4 \pm 0,5$
20

Histoequivalent-bioplastic material G-DERM

$15,6 \pm 1,1$

20

$5,1 \pm 0,9$ 